\title{
Classification Study on Relative Permeability Curves
}

\author{
Pingzhi Gong, Bin Liu, Junting Zhang, Zheng Lv, Guohao Zhang \\ CNOOC China Limited, Tianjin Branch, Tianjin, China \\ Email:162023044@qq.com
}

How to cite this paper: Gong, P.Z., Liu, B. Zhang, J.T., Lv, Z. and Zhang, G.H. (2018) Classification Study on Relative Permeability Curves. World Journal of Engineering and Technology, 6, 723-737. https://doi.org/10.4236/wjet.2018.64047

Received: August 22, 2018

Accepted: September 26, 2018

Published: September 29, 2018

Copyright ( $) 2018$ by authors and Scientific Research Publishing Inc. This work is licensed under the Creative Commons Attribution International License (CC BY 4.0).

http://creativecommons.org/licenses/by/4.0/

(c) (i) Open Access

\begin{abstract}
The classification method of relative permeability curves is rarely reported, when relative permeability curves are applied; if the multiple relative permeability curves are normalized directly, but not classified, the calculated result maybe cause a large error. For example, the relationship curve between oil displacement efficiency and water cut, which derived from the relative permeability curve in LD oilfield is uncertain in the shape of low water cut stage. If being directly normalized, the result of the interpretation of the water flooded zone is very high. In this study, two problems were solved: 1) The mathematical equation of the relationship between oil displacement efficiency and water cut was deduced, and repaired the lost data of oil displacement efficiency and water cut curve, which solve the problem of uncertain curve shape. After analysis, the reason why the curve is not available is that relative permeability curves are not classified and optimized; 2) Two kinds of classification and evaluation methods of relative permeability curve were put forward, the direct evaluation method and the analogy method; it can get the typical relative permeability curve by identifying abnormal curve.
\end{abstract}

\section{Keywords}

Relative Permeability Curve, Displacement Efficiency, Classification, Correction

\section{Introduction}

There are few reports on the classification of relative permeability curves, and the static parameter method represented by J function is common, but the relative permeability curve is the core of static and dynamic transformation. Static parameters alone are not sufficient to describe the full meaning of the curve, such as the law of water cut rising, etc. Based on the relative permeability curve 
of water phase, Wang Guoxian and Wang Lijun [1] [2] divided the relative permeability curve into five categories, and analysed the geological characteristics of each curve. He Jianmin [3] summarized and analyzed the reasons of abnormal curve, but did not give recognition and repair method of abnormal curve.

In the water flooding experiment, when the water is produced, the water content is higher, so there is no experimental data in the low water cut stage (Figure 1 ), and there is uncertainty in the shape of the curve (Figure 1 and Figure 2). Although the missing curves can be repaired by the normalization [4] [5] [6] [7] of the relative permeability curves, the results of the interpretation of the waterline layer are higher and the error is larger.

Generally, the lower the viscosity of crude oil is, the slower the increase rate of water cut is [8] [9] [10] [11]. The crude oil viscosity is $13 \mathrm{mPa} \cdot \mathrm{s}$ in LD oilfield and $50 \mathrm{mPa} \cdot \mathrm{s}$ in $\mathrm{SZ}$ oilfield. However, the relationship between oil displacement efficiency and water content in the two oilfields shows the abnormal phenomenon that water cut rises faster in low water content stage in LD oilfield (Figure 3) and this phase is exactly the missing piece of experimental data. The reason is that there may be abnormal curves in many relative permeability curves, which

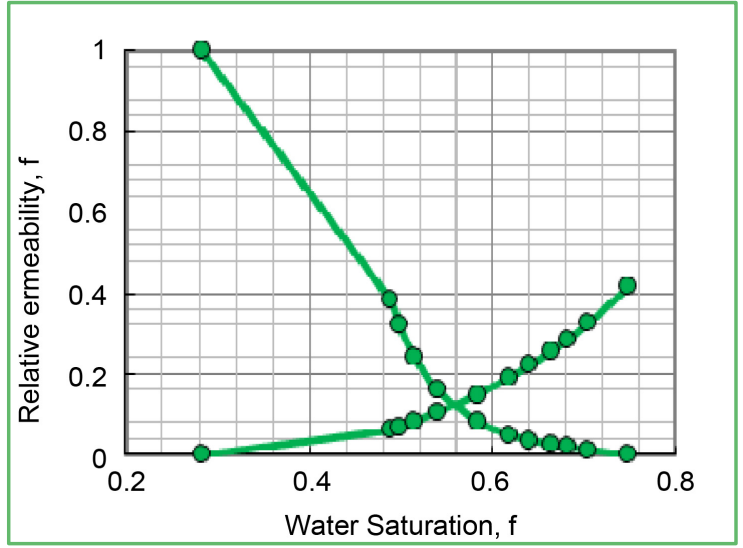

Figure 1. The relative permeability curve in LD oilfield.

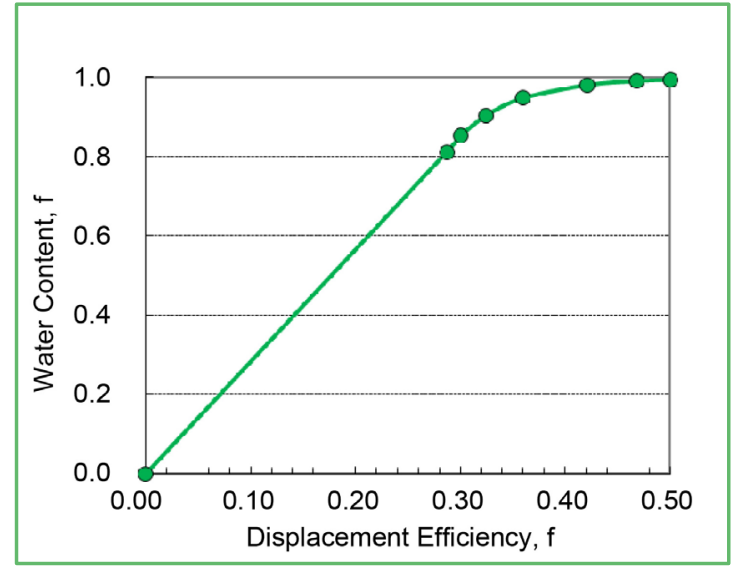

Figure 2. The oil displacement efficiency and water cut curve. 


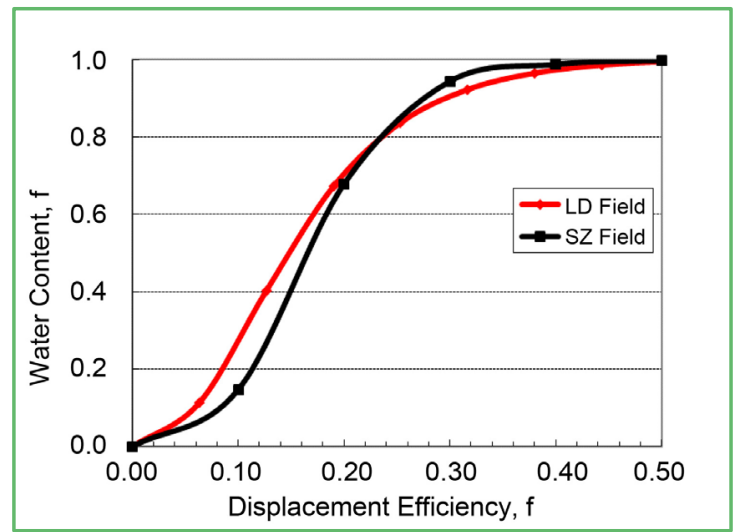

Figure 3. Comparison of oil displacement efficiency and water cut curve.

need to be optimized and corrected [12] [13] [14].

Based on the actual production of oilfields, two classification methods are proposed to optimize the relative permeability curves, and the two methods are combined; recognition gives the abnormal curve, thus obtaining the representative curve of oil field, and then guides the development and production of oil fields.

\section{Derivation of Mathematical Relationship between Oil Displacement Efficiency and Water Cut}

The oil-water two-phase relative permeability curve expression [15] [16] [17] [18] is:

$$
\frac{K_{r o}}{K_{r w}}=a \mathrm{e}^{b S_{w}}
$$

where $K_{r o}$ is relative permeability of oil phase, $K_{r W}$ is relative permeability of water phase, $S_{w}$ is water saturation.

According to the fractional flow equation, under the condition of ignoring the effects of capillary force, gravity and dissolved gas, the water cut can be expressed as:

$$
f_{w}=\frac{Q_{o}}{Q_{w}+Q_{o}}=\frac{1}{1+\frac{\mu_{w} \cdot K_{r o}}{\mu_{o} \cdot K_{r w}}}
$$

where $f_{w}$ is water content. $Q_{o}$ is daily oil production, the unit is $\mathrm{m}^{3} / \mathrm{d} . Q_{w}$ is daily water production, the unit is $\mathrm{m}^{3} / \mathrm{d} . \mu_{o}$ is oil viscosity, the unit is $\mathrm{mPa} \cdot \mathrm{s} . \mu_{w}$ is water viscosity, the unit is $\mathrm{mPa} \cdot \mathrm{s}$.

The oil displacement efficiency expression is:

$$
\eta=\frac{S_{w i}}{1-S_{w i}}
$$

where $\eta$ is oil displacement efficiency. $S_{w i}$ is original oil saturation.

The relationship between oil displacement efficiency and water content can be 
obtained by simultaneous solving the above three equations:

$$
f_{w}=\frac{1}{1+a \mathrm{e}^{b\left(1-S_{w i}\right) \eta+b S_{w i}}}
$$

In the above formula, $a, b$ and $S_{w i}$ are constants, let $A=a, B=b\left(1-S_{w i}\right)$ and $C=b \cdot s_{w i}$, so simplify it to:

$$
f_{w}=\frac{1}{1+A \mathrm{e}^{B \eta+C}}
$$

Take the logarithm:

$$
\ln \left(\frac{1}{f_{w}}-1\right)=B \eta+C+\ln (A)
$$

In the above formula, $B$ and $C+\ln (A)$ are constants, let $\alpha=B$, $\beta=C+\ln (A)$, so they can be simplified to:

$$
\ln \left(\frac{1}{f_{w}}-1\right)=\alpha \eta+\beta
$$

The above formula is the mathematical expression of oil displacement efficiency and water content, and it can be seen from the expression that oil displacement efficiency and the logarithm of water content are linear. By fitting curve, the exact expression of the displacement efficiency and water cut can be determined, and then the curve form is completed.

\section{Mathematical Relationship Verification between Oil Displacement Efficiency and Water Cut}

As the largest oilfield in Bohai sea, SZ oilfield has accumulated a lot of experience in the interpretation of water-flooded layers. In order to verify the correctness of the derived mathematical equation of oil displacement efficiency and water content, it is applied to SZ oil field first, and then to guide the application of the equation in LD oil field.

The relative permeability curve of SZ oilfield is shown in Figure 4. Figure 5 is a linear relationship between oil displacement efficiency and water content corresponding to relative permeability curve.

According to Figure 5 linear fitting relation, the mathematical relation between oil displacement efficiency and water content is obtained.:

$$
\ln \left(\frac{1}{f_{w}}-1\right)=-19.353 \eta+3.353
$$

The relation curve between oil displacement efficiency and water content can be calculated by using the above formula, and its calculated value and actual value are compared as shown in Figure 6. It can be seen from the figure that the fitting effect is very good.

However, LD oilfield is the case of missing data points in front (Figure 2), so the first two data points in SZ oilfield are removed (Figure 7) to simulate the situation of LD (Figure 2). The relationship between oil displacement efficiency 


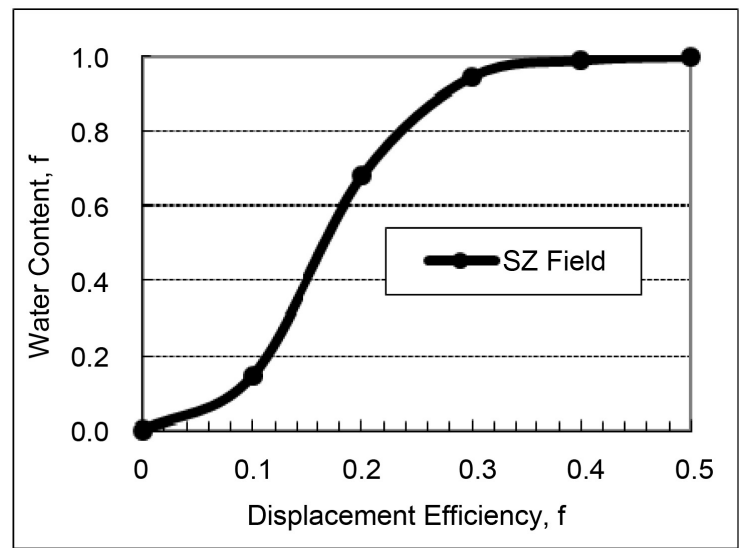

Figure 4. Oil displacement efficiency and water cut curve in SZ oilfield.

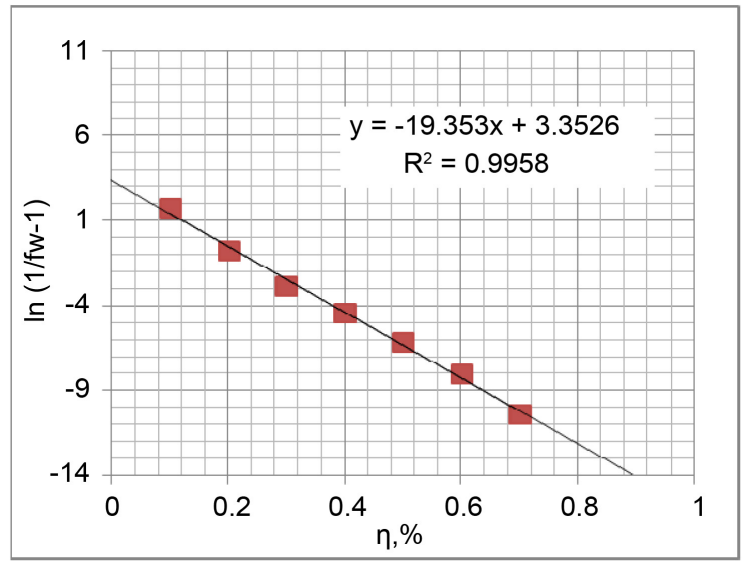

Figure 5. Fitting of linear relationship between oil displacement efficiency and water cut.

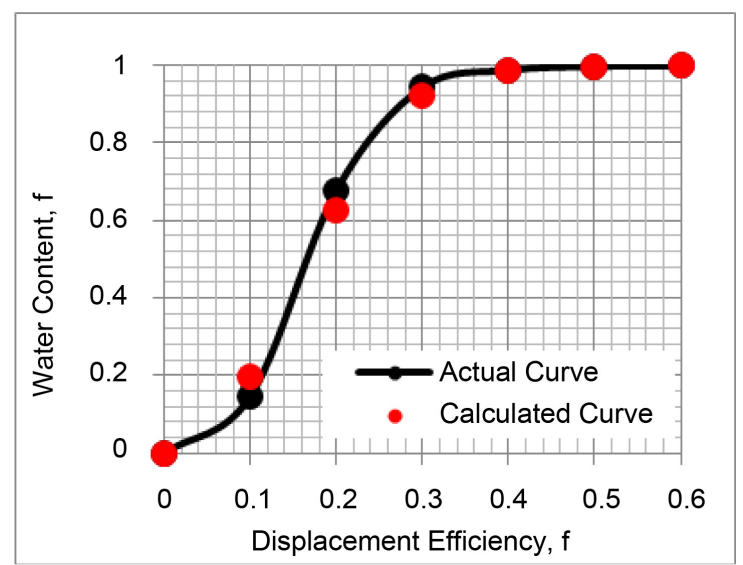

Figure 6. Fitting result of oil displacement efficiency and water cut curve.

and water content can be obtained by fitting the relationship between oil displacement efficiency and water content (Figure 8), the gray point in Figure 8 is the point removed: 


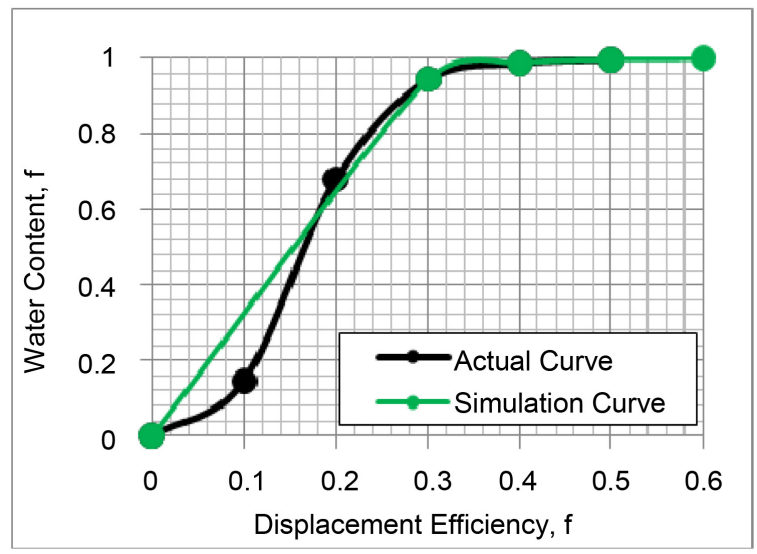

Figure 7. Oil Displacement efficiency and water cut curve in SZ oilfield.

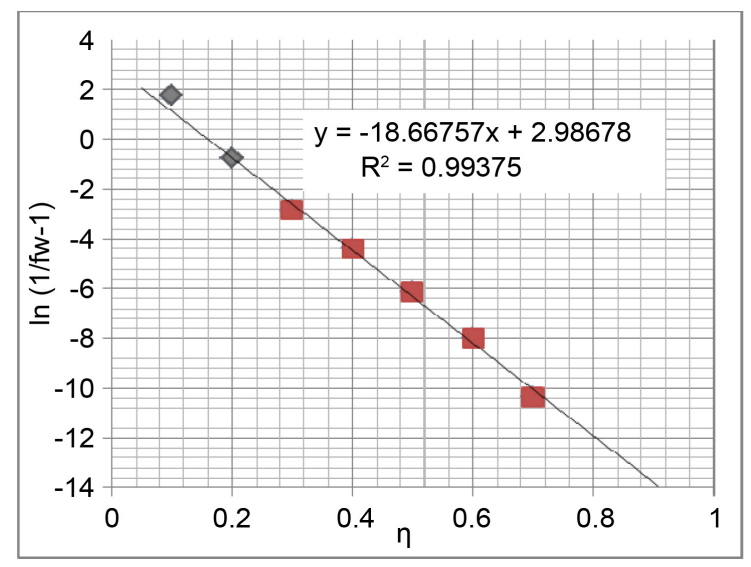

Figure 8. Linear relation fitting.

$$
\ln \left(\frac{1}{f_{w}}-1\right)=-18.668 \eta+2.987
$$

The curve of the orange curve in Figure 9 is a repaired curve. It is shown that the curve is different from the actual curve at low water cut stage, and further correction is needed.

\section{Mathematical Relationship Correction between Oil Displacement Efficiency and Water Cut}

The exponent part of Formula (5) is:

$$
y=\mathrm{e}^{b \eta+C}
$$

The above formula is drawn as Figure 10. After analysis, the reason why the error in the low water cut stage is greater is that the smaller the oil displacement efficiency, the faster the index ( $Y$ value in Figure 10) rises, so the error is bigger. The cause of the error is found, and then the curve can be corrected.

By observation, in Figure 11, all data points are approximately central symmetry with respect to the central point, so that the exact values of the missing 


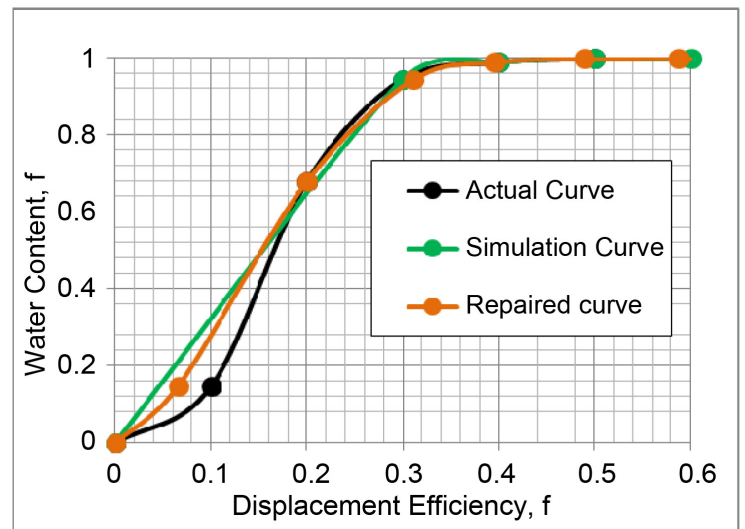

Figure 9. Repaired curves.

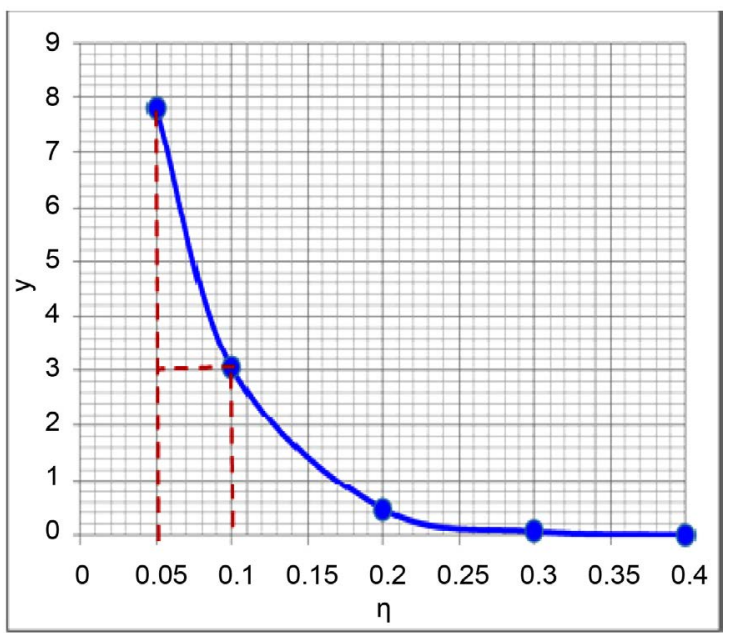

Figure 10. Calculation error analysis.

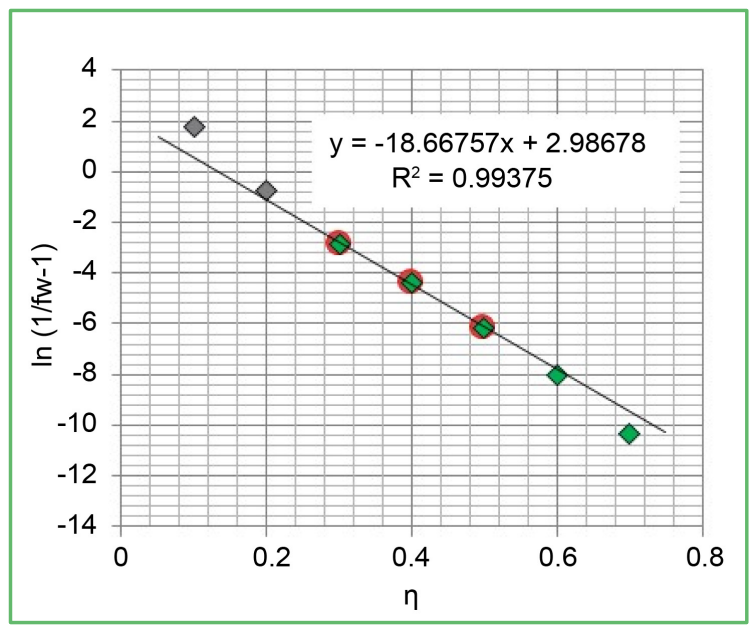

Figure 11. Linear relation fitting.

points can be estimated based on the triangle similarity principle. A simple diagram is shown in Figure 12. The comparison before and after the correction is shown in Figure 13. It can be seen that the curve error after correction is small 


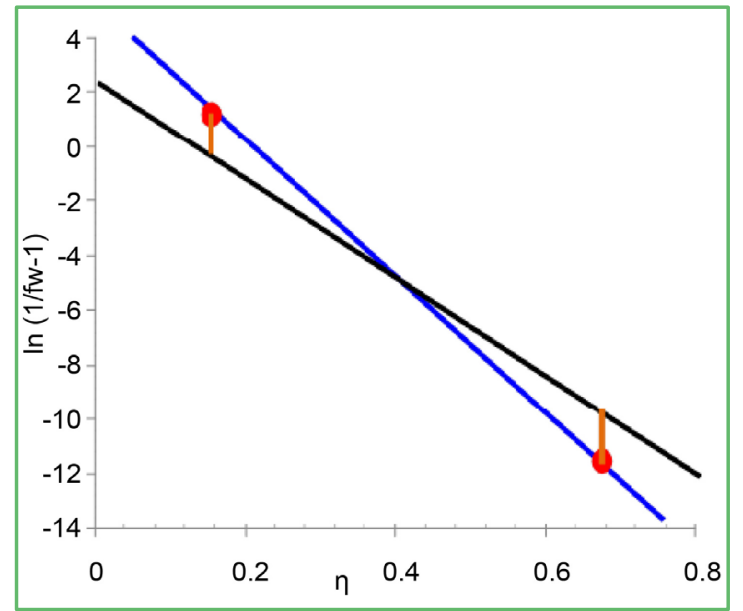

Figure 12. Schematic diagram of error analysis.

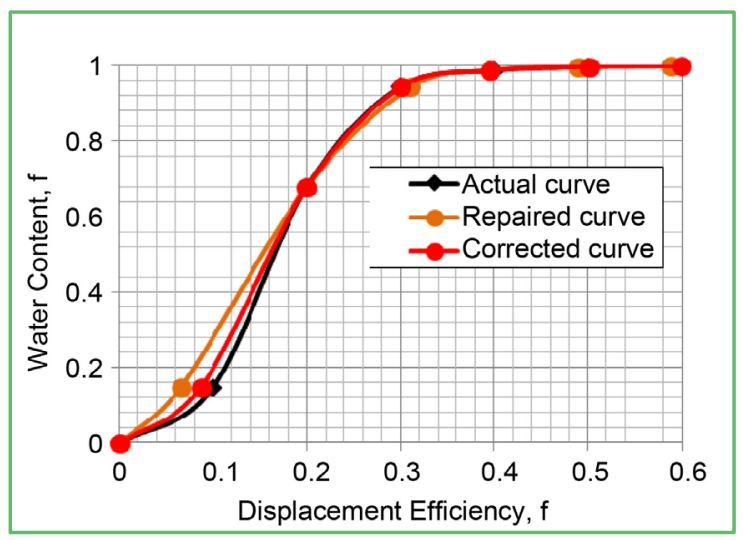

Figure 13. Comparison before and after curve correction.

and the maximum error is only about $5 \%$, which can be used for the interpretation of the water flooded layer. The correctness of the mathematical equation of oil displacement efficiency and water content is proved.

There are 4 relative permeability curves in LD oilfield. After correction, as shown in Figure 14, the water content range is $20 \%$ to $48 \%$, when the displacement efficiency is $88 \%$. The data span is large. Therefore, if the relative permeability curve is normalized directly for use, the accuracy of the results of interpretation is difficult to ensure, there will be a large error. The curve must be corrected.

Therefore, the reason for the high interpretation result of the water flooded layer is that the relative permeability curve has not been classified and optimized, and the water content has increased faster than the heavy oil field.

\section{Classification Evaluation Method of the Relative Permeability Curve}

\subsection{Conventional Classification Method}

The common classification method of relative permeability curve is a static 


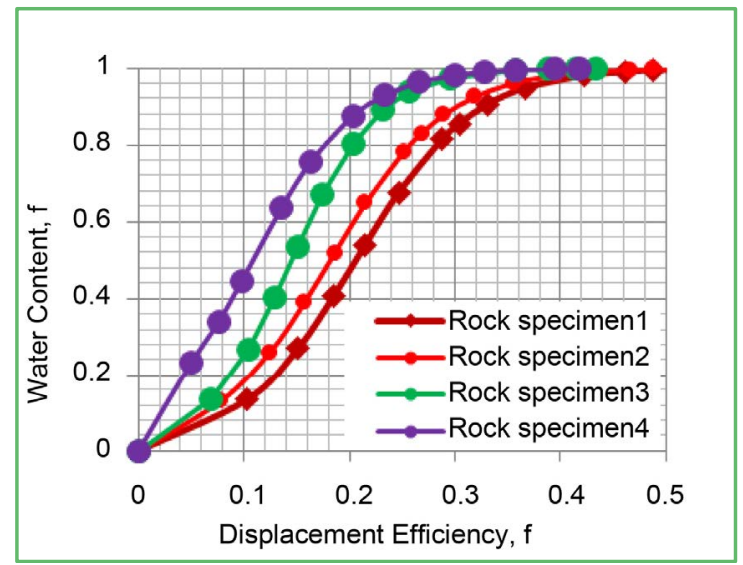

Figure 14. The oil displacement efficiency and water cut curve.

parameter method represented by J function [19] [20], which is classified according to the value of $\sqrt{K / \Phi}$. The classification results of LD oilfield are as follows.

Comparing the classification data (Table 1) with the oil displacement efficiency and water cut curve (Figure 14), we can see that there is no regularity between the data and the curve shape. This is because the conventional classification method is only based on the geological static parameters, and the relative permeability curve contains both geological and dynamic parameters. It is the central link of static and dynamic transformation. Therefore, only static parameters are used to classify the curve, it is not enough to describe all the information represented by the relative permeability curve, and there are certain defects.

\subsection{Direct Evaluation Method}

Take the logarithm of both sides of Formula (1):

$$
\ln \left(\frac{K_{r o}}{K_{r w}}\right)=b s_{w}+\ln a
$$

The above formula can be transformed into:

$$
\frac{K_{r o}}{K_{r w}}=\mathrm{e}^{b s_{w}+\ln a}
$$

The slope and intercept of the Formula (11), and the exponential part of the Formula (12) are related to the shape of the oil-water relative permeability curve, so the slope, intercept and index can quantitatively characterize the morphology of the curve, and they can be used as a basis for the classification of relative permeability curves. It can be seen from mathematical expressions that the ratio of oil-water relative permeability has a linear relationship with water saturation (Formula 11). According to relative permeability curve data, draw a straight line diagram as follows:

The mathematical relationship is as follows: 
Table 1. Classification data of relative permeability curves in LD oilfield.

\begin{tabular}{ccccc}
\hline Rock Sample & $\begin{array}{c}\text { Depth } \\
(\mathrm{m})\end{array}$ & $\begin{array}{c}\text { Air Permeability } \\
(\mathrm{mD})\end{array}$ & $\begin{array}{c}\text { Porosity } \\
\%\end{array}$ & $\sqrt{K / \Phi}$ \\
\hline Rock Sample 1 & 1558 & 8310 & 31.0 & 16.4 \\
Rock Sample 2 & 1571 & 6020 & 32.0 & 13.7 \\
Rock Sample 3 & 1578 & 2840 & 29.4 & 9.8 \\
Rock Sample 4 & 1584 & 4830 & 29.5 & 12.8 \\
Average & 1573 & 5500 & 30.5 & 13.4 \\
\hline
\end{tabular}

$$
\begin{aligned}
& \ln \left(\frac{K_{r o}}{K_{r w}}\right)=-21.35 s_{w}+11.94 \\
& \ln \left(\frac{K_{r o}}{K_{r w}}\right)=-22.82 s_{w}+12.84 \\
& \ln \left(\frac{K_{r o}}{K_{r w}}\right)=-32.89 s_{w}+19.55 \\
& \ln \left(\frac{K_{r o}}{K_{r w}}\right)=-21.42 s_{w}+12.74
\end{aligned}
$$

The slope, intercept and index statistics of each line are as follows.

It can be seen from Table 2 that the slope and intercept of the rock sample 3 are greater than the values of the other three samples. The slope values of the other three rock samples are about 22 , and the intercept value is about 12 . In Figure 15, the straight line of the rock sample 3 intersects the straight lines of the remaining three rock samples. By comparing the index values corresponding to different water saturations, the values of rock samples 1 and 2 are always close, so rock samples 1 and 2 can be divided into one class.

\subsection{Analogy Method}

By analogy with the curve of oil field with slightly larger viscosity, the curve can be classified qualitatively according to the rising law of water content. The comparison of each oil displacement efficiency and water cut curve of LD oilfield is shown in Figure 16. The black curve in Figure 16 is for the SZ field, the viscosity of the crude oil is $50 \mathrm{mPa} \cdot \mathrm{s}$, and the viscosity of the LD field is $13 \mathrm{mPa} \cdot \mathrm{s}$. Compared with the curve of the SZ oilfield, it can be found that the rock samples 1 and 2 can be divided into one class, and the rock samples 3 and 4 are divided into one class.

According to the influence of viscosity on the rising rate of water, it can be qualitatively judged from Figure 16 that the curves of rock samples 1 and 2 are reasonable, because water cut is rising more slowly, so they are the representative curves of LD oilfield. The red curve in Figure 17 is the result of normalization of the rock sample 1 and 2 curves. The green curve is unoptimized; it is the result of direct normalization of the four curves. 
Table 2. Statistical table of characteristic value of relative permeability curves.

\begin{tabular}{cccccc}
\hline $\begin{array}{c}\text { Water } \\
\text { Saturation }\end{array}$ & Characteristic Value & $\begin{array}{c}\text { Rock } \\
\text { Sample 1 }\end{array}$ & $\begin{array}{c}\text { Rock } \\
\text { Sample 2 }\end{array}$ & $\begin{array}{c}\text { Rock } \\
\text { Sample 3 }\end{array}$ & $\begin{array}{c}\text { Rock } \\
\text { Sample 4 }\end{array}$ \\
\hline Slope & -21.35 & -22.82 & -32.89 & -21.42 \\
0.4 & Intercept & 11.91 & 12.84 & 19.55 & 12.74 \\
0.5 & Index & 3.37 & 3.71 & 6.39 & 4.17 \\
0.6 & Index & 1.24 & 1.43 & 3.11 & 2.03 \\
0.7 & Index & -0.90 & -0.85 & -0.18 & -0.11 \\
\hline
\end{tabular}

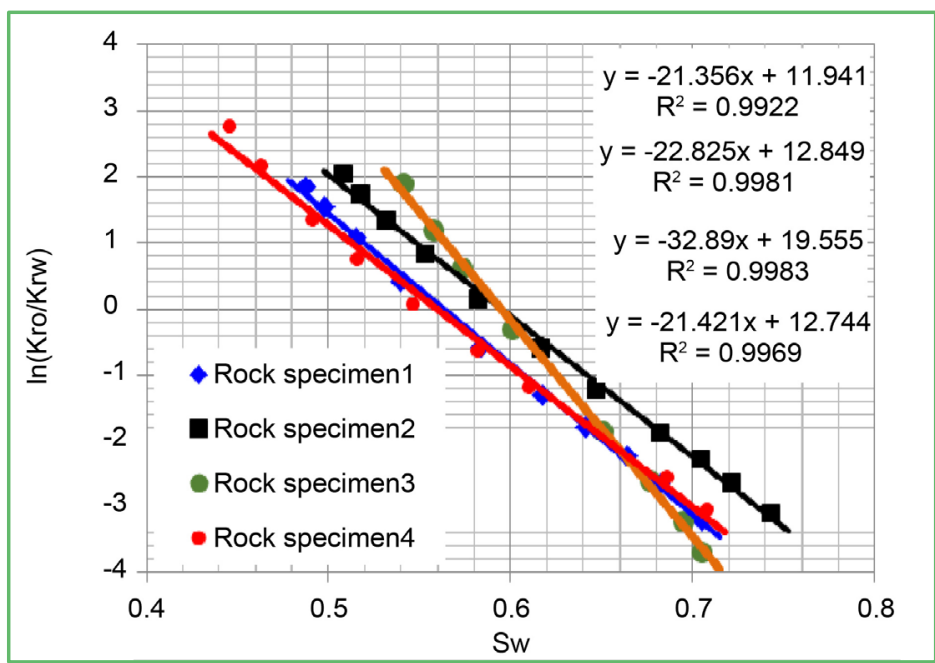

Figure 15. Fitting of linear relation of relative permeability curve.

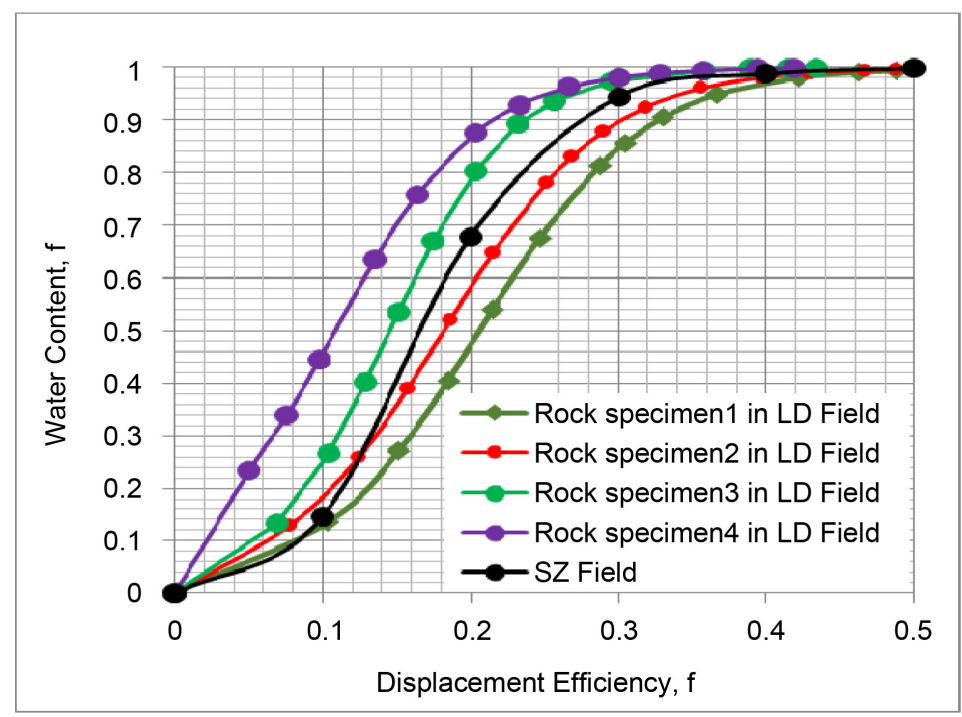

Figure 16. The oil displacement efficiency and water cut curve.

As can be seen from Figure 17, the difference between the red and green curves is very obvious, and the calculation accuracy of the relative permeability curve can be improved by classification, especially for the interpretation of the 


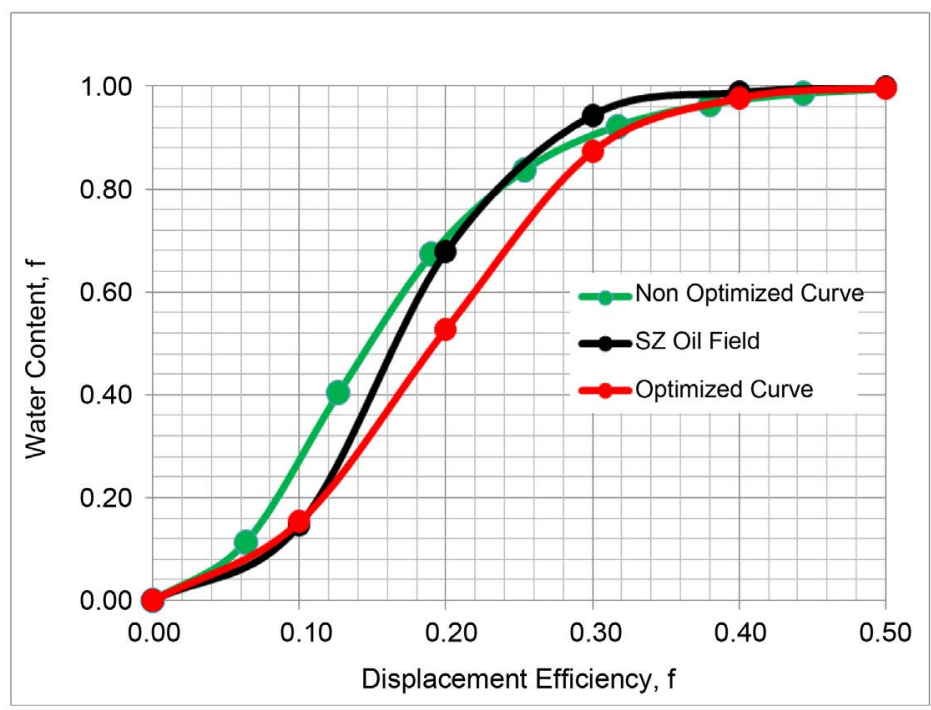

Figure 17. Comparison of curves before and after optimization.

water flooded layer. With the development of oil field into the middle and late period, it is more and more difficult to comprehensive adjustment. This requires more and more fine research by reservoir engineers. By studying the classification of relative permeability curve, the accuracy of application of the curve can be guaranteed.

\section{Application}

\subsection{Historical Fitting of Numerical Simulation}

The relative permeability curves before and after optimization were put into the CMG numerical simulation software to calculate the water cut of a well. The comparison results are shown in Figure 18. It can be seen that the fitting effect of the optimized relative permeability curve is better than that before optimization, thus reducing the workload of numerical simulation parameters adjustment. In addition, it was applied to the interpretation of water flooded zones in oilfield adjustment wells, which guided the optimization of perforation project and achieved good development results.

\subsection{Law of Water Cut Rising}

Using the fractional flow Formula (17), combined with the water injection development process, the average water saturation of oil layer can be expressed by the Formula (18). According to the two standardization results of LD oilfield, the theoretical curve of water content and water cut rising rate can be calculated by using Formula (17) and Formula (19), the comparison with the actual production data is shown in Figure 19.

$$
f_{w}=\frac{1}{1+\frac{\mu_{w} \cdot K_{r o}}{\mu_{o} \cdot K_{r w}}}
$$




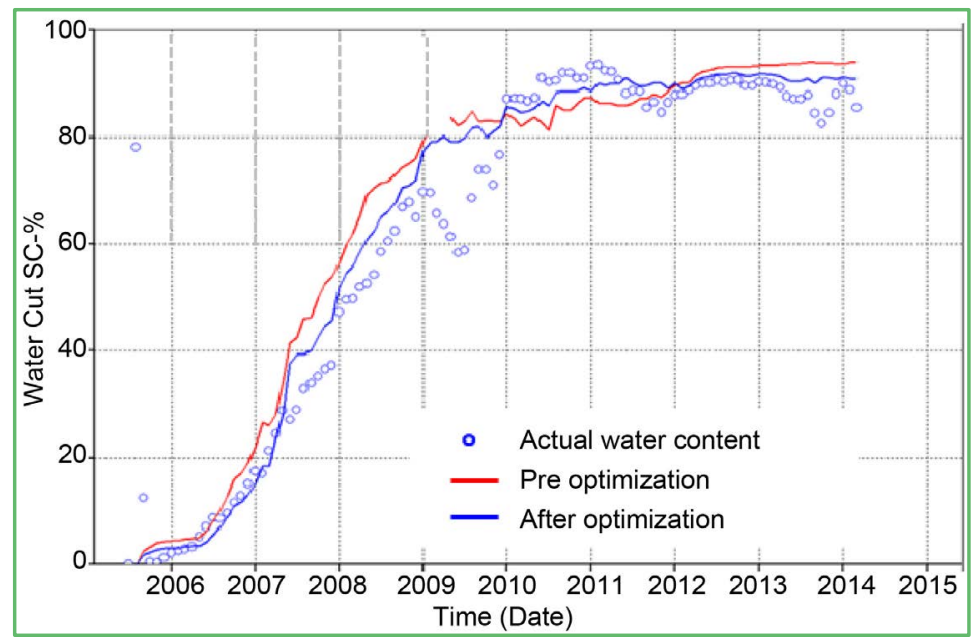

Figure 18. Comparison of numerical simulation results.

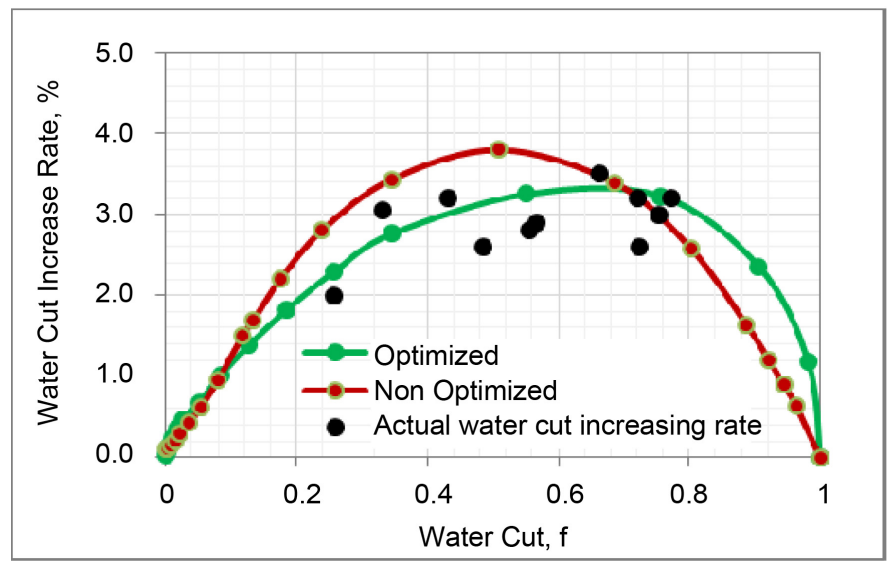

Figure 19. Relationship curve between water cut rise rate and water content.

$$
S_{w}=\frac{N_{P}}{N}\left(1-S_{w i}\right)+S_{w i}
$$

where $N_{P}$ is cumulative oil production, the unit is $\mathrm{m}^{3} . N$ is petroleum geological reserves, the unit is $\mathrm{m}^{3}$.

$$
f_{w}^{\prime}=\frac{f_{w 2}-f_{w 1}}{R_{f 2}-R_{f 1}} \cdot \frac{1-S_{w i}}{1-S_{w i}-S_{o r}}
$$

where $f_{w}^{\prime}$ is Water content derivative, $R_{f}$ is recovery percent, $S_{o r}$ is residual oil saturation.

As can be seen from Figure 19, theoretical curve of water content and water cut rising rate obtained from the optimized relative permeability curve is in good agreement with the actual situation of the oil field. It shows that this method is more in line with the actual oil-water migration law of reservoir.

\section{Conclusions}

1) The mathematical model of oil displacement efficiency and water cut has 
been deduced by combining the equation of the fractional flow equation, oil displacement efficiency and relative permeability curve. The correctness of the equation is verified by the data of relative permeability curve in $\mathrm{SZ}$ oilfield.

2) Two methods of classification and evaluation of relative permeability curves are proposed: direct evaluation and analogy method. The direct evaluation method can classify the curve quantitatively according to the characteristic value, and the analogy method can classify the curves qualitatively according to the law of the effect of viscosity on water cut rise. In the practical application process, it is necessary to combine the two methods to identify the abnormal curve, so as to obtain the representative relative permeability curve of the oilfield. The classification and optimization can ensure the accuracy of the application of the relative permeability curve, especially for the interpretation of the water flooded layer.

3) The classification method of relative permeability curve was applied to LD oilfield, and a representative relative permeability curve was obtained. By using the direct evaluation method, the multiple relative permeability curves were divided into two categories, and then the curve which is more in line with the law of water rising was chosen by analogy. It is proved by practical application that the optimized relative permeability curve is more in line with the actual oil field and more representative.

\section{Conflicts of Interest}

The authors declare no conflicts of interest regarding the publication of this paper.

\section{References}

[1] Wang, G.X. (2004) On Relative Permeability Curves and Production Characteristics of Reservoirs. XINJIANG Petroleum Geology, 25, 301-304.

[2] Wang, L.J. (2012) Analysis of Oil-Water Relative Permeability Curve's Characteristics. Science Technology and Engineering, 12, 2160-2162.

[3] He, J.M. (2009) Discussion on the Factors Affecting the Abnormal Permeability Curve of Oil and Water. Petroleum Geology and Recovery Efficiency, 16, 74-80.

[4] Chen, Y.Q. (1990) Standardization on the Curves of Permeability and Capillary Pressure. Petroleum Geology and Experiment, 12, 64-70.

[5] Miao, F., Liu, X., Zhang, H., Geng, N., Qiu, T., et al. (2013) Evaluation on Standardized Methods of Original Relative Permeability Curves. Fault-Block Oil \& Gas Field, 20, 759-762.

[6] Chen, Y.Q. (1990) A Standardized Method for the Average Relative Permeability Curve. Standards and Measurements in Petroleum Industry, 3, 6-9.

[7] Miao, F.F., Liu, X.H. and Zhang, H.Y. (2013) Evaluation on Standardized Methods of Original Relative permeability Curves. Fault-Block Oil \& Gas Field, 20, 759-762.

[8] Wang, S.L., Ai fen, L.I., Peng, R.G., et al. (2017) Effect of Oil Water Viscosity Ratio on Heavy Oil-Water Relative Permeability Curve. Science Technology and Engineering, 17, 86-90. 
[9] Yang, X.Y., Yang, S.L. and Li, X.L. (2011) Affecting Factors of Relative Permeability Curve in Heavy Oil Reservoir. Fault-Block Oil \& Gas Field, 18, 758-760.

[10] Zhang, B., Pu, C.S. and Zhu, J.H. (2013) Effect of Temperature on the Oil/Water Relative Permeability of Heavy Oil of Different Viscosity. Journal of Xi an Shiyou University (Natural Science Edition), 28, 61-62.

[11] Sun, Y.Y. (2017) Analysis on Influence Factors of Oil-Water Relative Permeability Curve in Low Permeability Reservoirs. Liaoning Chemical Industry, 46, 53-55.

[12] Peng, C.Z. and Xue, X.N. (2018) Experimental Data Processing Method of the Oil-Water Relative Permeabilities by Unsteady State Method. Petroleum Geology and Oilfield Development in Daqing, 37, 74-78.

[13] Zhang, J.C. and Song, K.P. (2007) Eigen Curve of Relative Permeability and Its Application. Acta Petrolei Sinica, 28, 104-107.

[14] Yang, X.P. (1998) A Method to Calculate the Relative Permeability Accurately. Petroleum Exploration and Development, 25, 63-66.

[15] Schneider, F.N. (1987) Three Procedures Enhance Relative Permeability Data. OGJ, 85, 45-51.

[16] Honarpour, M., Keodaritz, L. and Harvey, A.H. (1989) Relative Permeability of Petroleum Reservoir. Petroleum Industry Press, Beijing.

[17] Pittman, E.D. (1996) Relationship of Porosity and Permeability to Various Parameters Derived from Mercury Injection-Capillary Pressure Curves for Sandstone. $A A P G, 76,191-198$.

[18] Zhang, J. (2013) Water Flooding Oilfield Production Prediction Model. Petroleum Industry Press, Beijing.

[19] Leverett, M.C. (1941) Capillary Behavior in Porous Solids. Transactions of the AIME, 142, 151-169.

[20] Osisanya, S.O. and Tiab, D. (2014) A New Approach for Obtaining J-Function in Clean and Shaly Reservoirs Using in Situ Measurement. Journal of Canadian Petroleum Technology, 40, 30-37. 